Relationship between late objective and subjective outcomes of holistic neurorehabilitation in patients with traumatic brain injury

\title{
Sarajuuri, Jaana
}

2018-12-06

Sarajuuri , J , Vink , M \& Tokola , K 2018 , ' Relationship between late objective and subjective outcomes of holistic neurorehabilitation in patients with traumatic brain injury ' , Brain Injury, vol. 32 , no. 13-14 , pp. 1749-1757 . https://doi.org/10.1080/02699052.2018.1539247

http://hdl.handle.net/10138/313101

https://doi.org/10.1080/02699052.2018.1539247

acceptedVersion

Downloaded from Helda, University of Helsinki institutional repository.

This is an electronic reprint of the original article.

This reprint may differ from the original in pagination and typographic detail.

Please cite the original version. 
Relationship between late objective and subjective outcomes of holistic neurorehabilitation in patients with traumatic brain injury

Jaana Sarajuuri ${ }^{1,2}$, Martie Vink ${ }^{3}$, Kari Tokola ${ }^{4}$

${ }^{1}$ Department of Clinical Neuropsychology and Psychology, Validia Rehabilitation Helsinki

Nordenskiöldinkatu 18, 00250, Helsinki, Finland

${ }^{2}$ University of Helsinki, Faculty of Medicine, Department of Psychology

PO Box 21, 00014 University of Helsinki, Finland

jaana.sarajuuri@gmail.com

ORCiD ID 0000-0002-6432-0295

${ }^{3}$ Reade Center for Rehabilitation and Rheumatology

Overtoom 283, 1054 HW, Amsterdam, the Netherlands

martie.vink@reade.nl

${ }^{4}$ UKK Institute for Health Promotion Research

Kaupinpuistonkatu 1, 33500 Tampere, Finland

kari.tokola@uta.fi

Corresponding author: Jaana Sarajuuri, University of Helsinki, PO Box 21 (Haartmaninkatu 3, room E215:18) jaana.sarajuuri@gmail.com 


\title{
Relationship between late objective and subjective outcomes of holistic neurorehabilitation in patients with traumatic brain injury
}

\begin{abstract}
Objective: To explore the relation between objectively measured outcomes of neurorehabilitation and subjective self-appraisal of those outcomes in patients with traumatic brain injury (TBI).
\end{abstract}

Methods: Forty-five adults (34 men; age at injury, mean \pm SD, $30.1 \pm 10.3$ years) with chronic moderate-to-severe TBI ( $9.7 \pm 5.5$ years from injury; posttraumatic amnesia, $80 \%$ over one week) from two rehabilitation centres, in two countries. The subjects have had to resume working at various levels of competence following post-acute comprehensive neuropsychologically oriented neurorehabilitation, and experienced no functionally incapacitating, medical or psychological problems, for a minimum of six months after discharge. Objective outcome measure was the level of work competence attained postrehabilitation transposed from the descriptions of the types of work attained by each subject into a number along a 10-point scale. Subjective outcome measure was the personal evaluations by ratings in six consequences of rehabilitation (effort during rehabilitation, meaning in life, productivity, acceptance, social life, and intimate relationships) along a 10point scale.

Results: The attained work competence was statistically significantly related to the subjective self-appraisal of the ability to establish intimate relationships [odds ratio (OR), 1.79; 95\% confidence interval (CI), 1.20-2.68; $P=.005]$. Otherwise no association between subjective ratings and the levels of work was found. Of the patients, $67 \%$ attained competitive, $22 \%$ subsidised, and $11 \%$ volunteer or sheltered work. The subjective self-rated outcomes of the 
patients were relatively good [median, lower quartile (Q1) - upper quartile (Q3): 8 to 9,7 to 8 - 8 to 9 out of 10]. The lowest ratings were observed for the ability to establish intimate relationships $(8,7-8$ out of 10$)$.

Conclusions: The results support the need to evaluate rehabilitation outcomes involving both objective measures and subjective appraisals of them. The findings suggest that community functioning and satisfaction with that are distinct aspects of the subjects' experience that must be considered in the evaluation of rehabilitation. It seems that comprehensive neurorehabilitation improve outcome, and TBI patients with tailored placements were largely satisfied with the areas of wellness in their life. Additional larger controlled studies are needed to clarify how composition of neurorehabilitation and individualisation in outcomes assessment might enhance the outcome of TBI rehabilitation.

Key words: Traumatic brain injury; Neuropsychology; Rehabilitation; Outcome assessment

\section{Relationship between late objective and subjective outcomes of holistic neurorehabilitation in patients with traumatic brain injury}

Worldwide, traumatic brain injury (TBI) is a leading cause of injury-related disability which often contributes to long-term and serious consequences on cognition and communication, behaviour, mood, motor skills, and general health conditions which have a profound effect on the quality of life (QoL) of the person injured, as well as on his or her family and friends, community, and society in general with substantial economic burden in health care. ${ }^{1-3}$ The sequela of TBI often lead to difficulties with activities of daily living, community integration,

employment, family functioning, social participation, and relationships. ${ }^{1-3} \mathrm{TBI}$ is associated 
with all ages, but crucially affects young people at their productive age. ${ }^{1-3}$ For many patients TBI can have a lifelong impact on health and well-being. ${ }^{3}$ Evidence on long-term studies suggests that patients with TBI can show improvement or deterioration of functional outcomes many years after injury. ${ }^{3,4}$ Moreover, TBI might be an important modifiable risk factor for a variety of neurological illnesses and late neurodegenerative disorders. ${ }^{3,5}$ Findings on potential changing long-term consequences could inform systems of care to target longterm health-management with proactive health-maintenance and rehabilitation interventions to improve health and QoL of patients suffering from TBI. ${ }^{2,6}$

Rehabilitation for patients with TBI is a complex process. Premorbid functioning, nature and severity of TBI, and levels of social support have an impact on it, and different rehabilitation interventions are appropriate at different phases after the injury. ${ }^{1-3}$ Rehabilitation after TBI should address many aspects of a brain injured individual with appropriate therapeutic interventions for cognitive, behavioural, emotional, interpersonal, and physical skills while increasing awareness and understanding of a new self with the goal of alleviating disability and handicapping conditions. ${ }^{3,7-10}$ Growing evidence states that the diversity of disability after TBI is best served through comprehensive, holistic, and neuropsychologically oriented rehabilitation programmes delivered by a multidisciplinary team, in close collaboration with the patient and family, in terms of reducing psychosocial problems and increasing community integration, productivity and employment..$^{3,11-17}$

TBI affect multiple outcome domains, and it is growingly evident that also the outcome assessment should be multidimensional to show treatment effects or serve as endpoints for clinical studies. ${ }^{3}$ However, composite measures of outcome are lacking and diverse measures for assessing outcome after TBI are available. Regardless, the use of combinations of measures is called for to guide improved clinical management after TBI. ${ }^{3}$ Traditionally, the 
emphasis in evaluating the efficacy of various rehabilitative interventions has been on objective (external) measures, such as psychometric test performance ${ }^{15}$ or community integration measures, social engagement, and productive activity or return to work. ${ }^{13,18-20}$ However, solely adopting an objective metric often does injustice to the values and goals of the person served. ${ }^{21}$ While there has already been a shift from psychometric to functional measures, there is still a need for further shift to include also subjective (experiential) measures, which reflect the consumer's perspective more adequately. ${ }^{22}$ In the evaluation of outcomes of TBI rehabilitation it has become increasingly essential to capture the patient's own perspective whether the activities targeted by rehabilitation are those most valued by the patients and contribute most to their QoL and subjective well-being. ${ }^{23,24}$

The relationship between subjective well-being and objective indicators of rehabilitation outcomes, such as community integration, has been explored in some studies. ${ }^{25-29}$ It seems that for the most part findings have shown only low or modest association between life satisfaction and components of community integration. ${ }^{25,27,29}$ Higher levels of any given community activity will not necessarily be valued by the individual him/herself, and may not be enough to improve life satisfaction. ${ }^{26}$ On the other hand, Heinemann and Whiteneck ${ }^{28}$ found that global life satisfaction was positively related to social integration and productivity. The lack or incongruity of association between community activities and the subjective appraisal of them is a major challenge to outcome measurement after TBI and has important implications for the targeting of rehabilitation interventions. ${ }^{26}$ In a cross-cultural, unpublished pilot study involving $201 \mathrm{TBI}$ patients, Ben-Yishay and collaborators ${ }^{30}$ sought to test whether the hypothesized association between an objective outcome of neuropsychological rehabilitation (level of work or productivity) and six subjective measures of self-appraisal (effort during rehabilitation, meaning in life, productivity, acceptance, social life, and intimate 
relationships) would be confirmed. They found that the level of work or productivity attained following discharge from comprehensive neuropsychological rehabilitation was associated with how patients rated themselves in the six subjective areas of self-appraisal.

The aim of the present study was to re-examine the claim of Ben-Yishay and collaborators ${ }^{30}$ that the objective outcome (level of work or productivity) were associated with the six subjective areas of self-appraisal in a group of TBI patients who underwent intensive holistic neuropsychologically oriented rehabilitation.

The study has been approved by the local institutional review boards in the Käpylä Rehabilitation centre and the Reade Centre for Rehabilitation and Rheumatology and conforms to Helsinki Declaration.

\section{Methods}

\section{$\underline{\text { Participants }}$}

The study sample consisted of adult TBI patients that were recruited from two post-acute comprehensive neurorehabilitation programmes in Europe, one sample from the Käpylä Rehabilitation Centre, Helsinki Finland, and the other sample from the Reade Centre for Rehabilitation, Amsterdam, the Netherlands. Both patient samples included patients who were consecutively admitted to the two programs. Both holistic neurorehabilitation programmes address cognitive, meta-cognitive, affective and interpersonal concerns within the settings of therapeutic community types of programmes. ${ }^{11,31}$ Psychotherapy and cognitive training are carried out in individual and group formats. In addition, important elements of the holistic programmes are tailored and supported work trials, as well as follow-up procedures. The objective is that the TBI individual may attain acceptance and find meaning in his or her life 
after rehabilitation. On completion of the programme, patients should also have substantial knowledge about TBI, giving them a sound basis for understanding and coping with TBIrelated changes and for participating in productive living according to their own best selfinterests. The pioneering works of Goldstein, ${ }^{32}$ Ben-Yishay, ${ }^{15}$ Diller, ${ }^{33}$ Christensen,,${ }^{16}$ Prigatano ${ }^{14}$ and their colleagues have provided both the theoretical rationale as well as the remedial and psychotherapeutic techniques for such programmes.

In addition to the holistic neuropsychological rehabilitation, both of the programs have a multidisciplinary staff, including physical therapists, and social workers or vocational therapists. Moreover, the staff of the Finnish program contains professionals in neurology, speech and language therapy, occupational therapy, art therapy and nursing. The patient-staff ratio in the Finnish program is $1: 1.5$, and in the Dutch program it is $1: 1$. The total number of treatment hours is approximately 150-160 hours in the Finnish inpatient program, and 220230 hours in the Dutch day treatment program. The Finnish INSURE programme (the Individualised Neuropsychological Subgroup Rehabilitation) has been described in detail elsewhere. ${ }^{13}$

The inclusion criteria in this study were (1) voluntary agreement to participate; (2) underwent systematic neuropsychological rehabilitative treatments in a holistic neurorehabilitation programme; (3) residing in their respective communities (i.e. not requiring custodial care); (4) resuming working in a capacity commensurate with their post rehabilitative abilities following a holistic neurorehabilitation programme for a minimum of six months after discharge; and (5) experiencing no functionally incapacitating medical or psychological problems following a holistic neurorehabilitation programme for a minimum of six months after discharge. 
Demographic and injury-related information was obtained from hospital files. The neuropsychologic sequelae of the patients consisted of various combinations of problems common to TBI, including tendency to fatigue, slowness of information processing, disorders of attention and concentration, disorders of learning and memory, disturbances in executive skills, difficulties in modulating affective states, and disorders of language communication. The patients were independent in their daily life activities and had only slight physical disabilities.

Patients’ pre-morbid personal, vocational and social adjustments were also estimated. Premorbid estimates of adjustment were based on clinical-team consensus among members of the respective teams along a 5-point rating scale (consistently good, mostly satisfactory, occasionally/slightly problematic, considerably problematic, and consistently troubled) by using hospital files and clinical interviews of the patients and their significant others. Patients' level of intellectual functioning (IQ) at the time of their attendance to the rehabilitation program was estimated from their neuropsychological assessment files on the of basis of neuropsychology staff consensus as follows: within the borderline range IQ over 65 to 80 ; the average range IQ over 80 to 110 ; the high average range IQ over 110 to 120 ; and the superior range, IQ over 120.

\section{$\underline{\text { Measures }}$}

Objective outcome measure. The staff neuropsychologists interviewed in detail the patients by phone to get adequate descriptions of their actual pre-injury occupation and the postrehabilitation type or scope of their productive activities. Attained types of work were 
transposed along a 10-point scale by an experienced neuropsychologist who was not involved in the patients' care (Appendix 1). For the purpose of statistical analysis, three categories of the levels of work attained post discharge were used: sheltered workshop or volunteer work (levels 1-4), subsidised work (levels 5-6), and competitive work (levels 7-10).

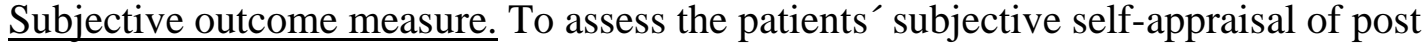
rehabilitation outcomes an evaluation instrument shown in table 1 and developed by BenYishay and Daniels-Zide ${ }^{18}$ was used. According to Ben-Yishay and Daniels-Zide extensive clinical experience has shown that the six items of the self-rating instrument tend to elicit clinically different but meaningful information. ${ }^{22}$ They point out that in contrast to previous indicators of self-appraisal that focused on pathological aspects of experience such as anxiety, anger, and depression, the notion of self-appraisal as a metric in defining rehabilitation outcomes with positive connotations has been requested, and has yet been taken into account in the recent development of QoL measurers of TBI. ${ }^{34-36}$

We mailed to the patients the self-evaluative rating scale with instructions to rate themselves in the six areas: effort during rehabilitation, meaning in life, productivity, acceptance, social life, and intimate relationships which was defined as closely acquainted or familiar. Patients were asked to rate the six areas along a 10-point scale from the best (a rating of 10) to the worst (a rating of 1) in a 2-week time in order to give them time to figure out their ratings. After that we phoned to the patients and asked the results of their self-ratings. If needed, we clarified to the patients the precise clinical meaning of the questions as intended in the study. Attention was especially paid to the clarification of the concept 'intimate relationships' meaning the self-appraised ability to establish close relationships in general and not only in a sense of a relationship to a partner. 


\section{$\underline{\text { Statistical Analysis }}$}

Descriptive statistics were used to characterize the participants. The values of the variables on the self-appraisal scale are presented as means, medians, quartiles [lower quartile (Q1), upper quartile (Q)], and minimums and maximums.

Because of non-normal distribution and small number of subjects, IQ and the subjective ratings were divided into three categories, and Kendall's Taus were calculated to assess the relationship between the 3-category IQ $(65-110,110-120$, over 120) and the subjective ratings which were also divided into three categories (cut-off points for categories vary depending on the variable). Univariate ordinal regression was used to assess the association between the six areas of self-appraisal as well as the sum of the self-appraisals and categorized level of work attained post discharge. Three categories for the levels of work attained post discharge were formed from the 10-point scale as 1-4 (sheltered workshop or volunteer work), 5-6 (subsidised work) and 7-10 (competitive work), and test of parallel lines was used for each model to make sure that proportional odds assumption holds (see Appendix 1).

To examine whether skewness of the distribution of the self-appraisals have an effect on the results, associations between the 3-category levels of work and the subjective self-appraisal of the areas of wellness following rehabilitation were verified by dividing each area of the subjective self-appraisal into two or three categories and using these categorical variables instead of numerical ones in the ordinal regression models as an explanatory variable. All statistical analyses were conducted using IBM SPSS statistics software version 22 (Chicago, IL). 
Results

A total of 57 consecutively admitted participants from the holistic programs (Finnish 35; Dutch 22) were invited to participate the study. Seven of the participants did not meet all the inclusion criteria, three were unwilling to participate, and two could not be reached. The characteristics of the 45 eligible patients (27 Finnish, 18 Dutch), 34 men and 11 women, with moderate to severe (percent posttraumatic amnesia, $80 \%$ over 1 week) TBI are shown in table 2. Their mean age was 30.1 years $( \pm \mathrm{SD}, 10.3 \mathrm{y}$; range, $15.0-52.0 \mathrm{y})$. The mean time since injury to evaluation was 9.7 years $( \pm \mathrm{SD}, 5.5 \mathrm{y}$; range, $4.0-36.0 \mathrm{y})$. At the time of the evaluation the mean time patients had been working after the holistic neurorehabilitation program was 4.7 years $( \pm \mathrm{SD}, 2.3 \mathrm{y}$; range, $0.7-8.0 \mathrm{y})$. The pre-injury estimated personal, vocational and social adjustments were within the 'consistently good' or the 'mostly satisfactory' range for $76 \%$ to $85 \%$ of the patients. The IQ levels of the patients within the average range were $44 \%$, and $40 \%$ of the patients with IQ levels above average range. The 3-category IQ was not significantly related to any of the 3-category subjective areas of self-appraisal.

Sixty-seven percent of the patients attained competitive employment, 54\% part-time and 13\% full-time work capacity. Twenty-two percent attained subsidized and $11 \%$ volunteer or sheltered workshop work ability. Figure1 shows the number of the patients classified according to the level of work competence achieved after rehabilitation.

Results of the self-appraisals in six areas of wellness following rehabilitation are presented in table 3. Median for the different areas of self-ratings was between 8 and 9 (Q1-Q3: 7 to 8-8 to 
9) out of 10. The lowest ratings were related to the ability to establish intimate relationships $(8,7-8$ out of 10$)$.

Associations between the subjective self-appraisals and the 3-category level of work are shown in table 4 . The subjective self-appraisal for the ability to establish intimate relationships had a significant association with the levels of work [odds ratio (OR), 1.79; 95\% confidence interval $(\mathrm{CI}), 1.20-2.68 ; P=0.005]$. Otherwise no association between other areas of subjective ratings and the levels of work attained by the subjects was found. Skewness of the distribution of the self-appraisals did not have an effect on the results.

\section{Discussion}

The main finding of the present study was that the levels of work obtained and the selfappraised ability to establish intimate relationships were associated for persons with TBI after holistic neurorehabilitation. The higher was the attained work ability (sheltered workshop or volunteer, subsidised work and competitive work) the better was the self-rated ability to establish intimate relationships. Otherwise, the levels of work were not associated with the subjective self-appraisals in the other areas.

The procedure to verify associations between the levels of work and the subjective selfappraisal of the areas of wellness following rehabilitation showed that the skewness of the distribution of the self-appraisals did not have an effect on the results, and still the ability to establish intimate relationships remained the only area of self-appraisal to have a significant association with the level of work attained. Results also showed that the self-rated ability to 
establish intimate or closely acquainted relationships had the lowest self-rating for the patients in both programmes. We think that this observation is important at a number of levels. Keeping a job and handling higher level responsibilities often means getting along with people and understanding their needs as well. Research on TBI and employment is full of examples of emotional dysregulation, behavioral problems and lack of awareness of one's deficits being particularly disabling in relation to achieving and maintaining gainful employment. ${ }^{37,38}$ These factors have also been perceived as barriers to relationships, in particularly intimate, after TBI. ${ }^{38}$ Especially mood swings, irritability states and unpredictable patterns of behaviour have been shown to impose the greatest strain on personal relationships. ${ }^{39,40}$ The neurobehavioural and emotional problems may actually be the major challenge for facing rehabilitation and for enhancing efforts at community adjustment, intimate relationships, productivity, and overall well-being in life after TBI. ${ }^{41}$

Given that the majority of subjective self-rated outcomes and the vocational outcome showed no significant relationship, our results are consistent with previous studies that have noted dissociation between functional outcomes and subjective well-being, especially for patients with chronic TBI. ${ }^{25,35,42}$ These findings again suggest that community functioning and satisfaction with functioning are distinct aspects of participants' experience that must be considered in the evaluation of rehabilitation for patients with TBI. The findings suggest that the relationship between objective indices of functional outcomes and subjective well-being is moderated by subjective meanings and values assigned by patients. This incongruity of association between objectively measured outcomes and subjective appraisals of them has implications for the targeting of rehabilitation interventions and places a challenge to outcomes measurement. The use of outcome measures that cover composite outcome domains is needed to guide improved clinical management after TBI. ${ }^{3,26}$ According to Ben-Yishay and 
Daniels-Zide ${ }^{22}$ conventional ways of viewing outcomes in terms of parameters of self-care, ambulation, speech, and ability to perform work-related tasks misses the bigger picture of rehabilitation, and also deprives professionals of a meaningful way to determine when and whether the person has reached full rehabilitation potential.

Of the 57 consecutively admitted patients who were invited to participate the study, five of the excluded patients were those who had not resumed working following discharge from holistic rehabilitation which was an inclusion criterion. This means that around $90 \%$ of all the patients had achieved at least some level of work competence and were productive after the rehabilitation. The rate of productivity is quite consistent with that found in the previous studies on the efficacy of comprehensive rehabilitation programmes for post-acute patients with TBI when also volunteer work and sheltered work were taken into account. ${ }^{9,14,16,18}$

Most of the patients (53\%) attained part-time competitive employment, and 31\% attained subsidised or volunteer work ability. Notably, only $13 \%$ attained full-time competitive employment and solely one of them could resume in a job for which he had received academic training pre-injury (as the most demanding level of work in the 10-point scale). Return to work (RTW) rates are highly variable across the literature. Despite advances in critical care and rehabilitation methods, changes in disability legislation, and increasingly important economic reasons, the research literature has constantly documented that RTW rates remain low. ${ }^{43,44}$ According to a recent systematic review of RTW studies conducted by van Velzen and colleagues ${ }^{43}$ on average, approximately $40 \%$ of TBI patients have achieved RTW at both the 1- and 2-year milestones, and notably, a substantial number of them were neither able to return to their former work or return permanently. As a result of a variety of cognitive, behavioural and emotional disorders; impaired psychosocial, physical and sensory 
functioning; and medical symptoms, individuals who sustain TBI often experience difficulty becoming competitively employed post injury and maintaining employment for extended period of time..$^{37,43,45}$

Essential elements in the holistic neurorehabilitation programmes are individually tailored placements and supported work trials which help patients to find productive activities that fit their abilities and interests after TBI. ${ }^{7,11,13,46}$ The effort to accomplish consistence between the capabilities of the patients and the requisites of the work or other productive activities seems to be crucial. Such interventions are used in a less systematic way - if at all — in traditional clinical care and rehabilitation. It is noteworthy, that RTW as such does not guarantee good psychosocial adjustment. ${ }^{47}$ ONeill et al. ${ }^{48}$ suggested that part-time employment might be superior to full-time employment after TBI. In their study, part-time workers had fewer unmet needs, were more socially integrated, and were more engaged in activities at home than fulltime workers. Full-time workers may have been so fully engaged in their work that they had less time and energy to pursue other life domains. These findings suggest that successful outcomes concerning productivity are related to the compatibility with the resources and capabilities of the patients after injuries. In our study the TBI patients with individually tailored placements were largely satisfied with the areas of wellness in their life even years after comprehensive holistic neurorehabilitation programmes.

The patients in our study were in a quite chronic phase, the mean time since TBI to evaluation being nearly 10 years (mean, 9.7 years $\pm S D, 5.5 y$; range, 4.0-36.0y), but not succeeded to resume working before the holistic neurorehabilitation programme. This note supports the previous findings that outcomes after TBI are not time bound and that individuals living with 
moderate-to-severe TBI can show improvement of functional outcomes many years after injury, and benefit from a long-term health-management approach ${ }^{3 .}$

Medians of the self-ratings for the different areas of well-being (effort during rehabilitation, meaning in life, productivity, acceptance, social life, and intimate relationships) were generally quite high; 8 to 9 out of 10 . These findings support the assumptions underlying comprehensive neurorehabilitation that it facilitates achievement of a successful outcome through the establishment of a meaningful and satisfactory life after TBI in the face of persisting limitations..$^{9,14,22}$

\section{$\underline{\text { Study limitations }}$}

This study has several limitations. The sample size was relatively small, which affects the generalisability of the findings. In addition, this study did not have a control group.

Nevertheless, the primary purpose of our study was not to assess the effectiveness of holistic neurorehabilitation, but to explore whether objectively measured successful outcomes of rehabilitation and the participants's subjective self-appraisal of those outcomes are associated. However, additional prospective controlled studies including also patients not involved in a holistic rehabilitation programme and looking at their ratings are needed.

\section{$\underline{\text { Future studies }}$}

Additional research is needed to evaluate the contents and benefits of different rehabilitation interventions. This study included only subjects who had resumed working at various levels of competence following rehabilitation. In future studies it would be interesting to explore how patients with different objective outcomes, or patients who have not attained work ability 
after rehabilitation, rate their subjective well-being or QoL. Further work is also needed to develop composite outcome assessments to instruct improved clinical management after TBI.

\section{Conclusions}

The findings support the need to evaluate rehabilitation outcomes involving both objective measures of outcomes as well as subjective measures of the patients' evaluations of the objective outcomes. These findings also suggest that community functioning and satisfaction with functioning are distinct aspects of participants' experience that must be considered in the evaluation of rehabilitation for patients with TBI. In addition, it seems that comprehensive neurorehabilitation does overcome handicaps and improve outcome after TBI, and that patients with individually tailored placements were largely satisfied with the areas of wellness in their life, even for patients who are many years post injury. Additional research is needed to clarify how individualisation in outcomes assessment and development of composite outcome assessment measures might enhance the outcome of TBI rehabilitation.

Acknowledgments: The authors wish to thank Professors Leonard Diller and Yehuda BenYishay, George Prigatano, PhD, Sanna Koskinen, PhD, Teppo Särkämö, PhD, and HannuVirtanen, MD, for their critical review of the study proposal and the manuscript.

Declaration of interest: The authors report no conflicts of interest.

References 
1. Centers for Disease Control and Prevention [Internet]. Traumatic brain injury in the United States: fact sheet. 2017 [cited 2017 Dec 18]. Available from: http://www.cdc.gov/TraumaticBrainInjury/get_the_facts.html.

2. Zasler ND, Douglas DI, Zafonte RD, editors. Brain injury medicine: principles and practice. 2nd ed. New York: Demos Medical Publishing; 2013.

3. Maas AI, Menon DK, Adelson PD, Andelic N, Bell MJ, Belli A, Bragge P, Brazinova A, Büki A, Chesnut RM, Citerio G, Coburn M, Cooper DJ, Crowder AT, Czeiter E, Czosnyka M, Diaz-Arrastia R, Dreier JP, Duhaime A-C, Ercole A, van Essen TA, Feigin VL, Gao G, Giacino J, Gonzalez-Lara LE, Gruen RL, Gupta D, Hartings JA, Hill S, Jiang J-y, Ketharanathan N, Kompanje EJ, Lanyon L, Laureys S, Lecky F, Levin H, Lingsma HF, Maegele M, Majdan M, Manley G, Marsteller J, Mascia L, McFadyen C, Mondello S, Newcombe V, Palotie A, Parizel PM, Peul W, Piercy J, Polinder S, Puybasset L, Rasmussen TE, Rossaint R, Smielewski P, Söderberg J, Stanworth SJ, Stein MB, von Steinbüchel N, Stewart W, Steyerberg EW, Stocchetti N, Synnot A, Ao BT, Tenovuo O, Theadom A, Tibboel D, Videtta W, Wang KK, Williams WH, Wilson L, Yaffe K, for the InTBIR Participants and Investigators. Traumatic brain injury: integrated approaches to improve prevention, clinicl care, and research. Lancet Neurol. 2017; published online November 6. http://dx.doi.org/10.1016/ S1474-4422(17)30371-X.

4. Corrigan JD, Hammond FM. Traumatic brain injury as a chronic health condition. Arch Phys Med Rehabil. 2013;94:1199-201.

5. Green RE. Editorial: brain injury as a neurodegenerative disorder. Front Hum Neurosci. 2015; 9:615. 
6. Wilson L, Stewart W, Dams-O’Connor K, Diaz-Arrastia R, Horton L, Menon DK, Polinder S. The chronic and evolving neurological consequences of traumatic brain injury. Lancet Neurol. 2017;6:813-25.

7. Prigatano GP. Principles of neuropsychological rehabilitation. New York: Oxford University Press; 1999.

8. Diller L. Pushing the frames of reference in traumatic brain injury rehabilitation. Arch Phys Med Rehabil. 2005;86:1075-80.

9. Cicerone KD, Tasha M, Azulay J, Sharlow-Galella MA, Ellmo WJ, Paradise S, Friel JC. A randomized controlled trial of holistic neuropsychologic rehabilitation after traumatic brain injury. Arch Phys Med Rehabil. 2008;89:2239-49.

10. Horn SD, Corrigan JD, Dijkers MP. Traumatic brain injury rehabilitation comparative effectiveness research: introduction to the traumatic brain injury practice based evidence. Arch Phys Med Rehabil. 2015;96(8 Suppl 3):S173-7.

11. Cicerone KD, Langenbahn DM, Braden C, Malec JF, Kalmar K, Fraas M, Felicetti T, Laatsch L, Harley JP, Bergquist T, Azulay J, Cantor J, Ashman T. Evidence-based cognitive rehabilitation: updated review of the literature from 2003 through 2008. Review article (Meta-analysis). Arch Phys Med Rehabil. 2011;92:519-30.

12. Geurtsen GJ, van Heugten CM, Martina JD, Geurts AC. Comprehensive rehabilitation programmes in the chronic phase after severe brain injury: a systematic review. Journal of Rehabilitation Medicine. 2010;42:97-110.

13. Sarajuuri J, Kaipio M-L, Koskinen S, Niemelä M, Servo A, Vilkki J. Outcome of a comprehensive neurorehabilitation program for patients with traumatic brain injury. Arch Phys Med Rehabil. 2005;86:2296-302. 
14. Prigatano GP, Klonoff PS, O’Brien KP, Altman IM, Amin K, Chiapello D, Shepherd J, Cunningham M, Mora M. Productivity after neuropsychologically oriented milieu rehabilitation. J Head Trauma Rehabil. 1994;9:91-102.

15. Ben-Yishay Y, Rattok J, Lakin P, Piasetsky EB, Ross B, Silver S, Zide E, Ezrachi O. Neuropsychologic rehabilitation: quest for a holistic approach. Semin Neurol. $1985 ; 5: 252-9$.

16. Christensen AL, Pinner EM, Møller Pedersen P, Teasdale TW, Trexler LE. Psychosocial outcome following individualized neuropsychological rehabilitation of brain damage. Acta Neurol Scand. 1992;85:32-8.

17. Holleman M, Vink M, Nijland R, Schmand B. Effects of intensive neuropsychological rehabilitation for acquired brain injury. Neuropsychological Rehabilitation. 2016;28:649-62, DOI: 10.1080/09602011.2016.1210013.

18. Ben-Yishay Y, Silver SM, Piasetsky E, Rattok J. Relationship between employability and vocational outcome after intensive holistic cognitive rehabilitation. J Head Trauma Rehabil. 1987;2:35-48.

19. Wehman P, West M, Johnson A, Cifu, DX. Vocational rehabilitation for individuals with traumatic brain injury. In: Rosenthal M, Griffith ER, Kreutzer JS, Pentland B, editors. Rehabilitation of the adult and child with traumatic brain injury. 3rd ed. Philadelphia: FA Davis; 1999. p. 326-41.

20. Doninger NA, Heinemann AW, Bode RK, Sokol K, Corrigan J, Moore D. Predicting community integration following traumatic brain injury with perceived health and cognitive status measures. Rehabilitation Psychology. 2003;48:67-76.

21. Brown M, Gordon WA. Empowerment in measurement: 'muscle', 'voice', and subjective quality of life as gold standard. Arch Phys Med Rehabil. 2004;85:13-20. 
22. Ben-Yishay Y, Daniels-Zide E. Examined lives: outcomes after holistic rehabilitation. Rehabilitation Psychology. 2000;45:112-29.

23. Bullinger M. Assessing health related quality of life in medicine. An overview over concepts, methods and applications in international research. Restor Neurol Neurosci. 2002;20:93-101.

24. Dijkers M. Quality of life after traumatic brain injury: a review of research approaches and findings. Arch Phys Med Rehabil. 2004;85:21-35.

25. Cicerone KD, Mott T, Azulay J, Friel JC. Community integration and satisfaction with functioning after intensive cognitive rehabilitation for traumatic brain injury. Arch Phys Med Rehabil. 2004;85:943-50.

26. Johnston MV, Goverover Y, Dijkers M. Community activities and individuals' satisfaction with them: quality of life in the first year after traumatic brain injury. Arch Phys Med Rehabil. 2005;86:735-45.

27. Corrigan JD, Bogner JA, Mysiw WJ, Clinchot D, Fugate L. Life satisfaction after traumatic brain injury. J Head Trauma Rehabil. 2001;16:543-55.

28. Heinemann AW, Whiteneck GG. Relationships among impairment, disability, handicap, and life satisfaction in persons with traumatic brain injury. J Head Trauma Rehabil. 1995;10:54-63.

29. Smith JL, Magill-Evas J, Brintnell A. Life satisfaction following traumatic brain injury. Can J Rehabil. 1998;11:131-40.

30. Ben-Yishay Y, Diller L, Daniels-Zide E, Bartfai A, Bracy O, Hoofien D, Keim R, Mazzuchi A, North P, Oddy M, Sarajuuri J, Siert L, Tolman S, Vink M. Correlates of self-appraisal with selected outcomes of neuropsychological rehabilitation: An international pilot study. In: Ben-Yishay Y, editor. Clinical studies in holistic 
neuropsychological rehabilitation. NYU, Brain Injury Day Program; 2010 [monograph].

31. Sarajuuri J, Koskinen S. Holistic neuropsychological rehabilitation in Finland: the INSURE program - a transcultural outgrowth of perspectives from Israel to Europe via the USA. Int J Psychology. 2006;41:362-70.

32. Goldstein K. After effects of brain injuries in war: their evaluation and treatment. New York: Grune \& Stratton; 1942.

33. Diller L. Neuropsychological rehabilitation. In: Meier MJ, Benton AL, Diller L, editors. Neuropsychological rehabilitation. London: Churchill-Livingstone; 1987. p. 117.

34. Truelle JL, Koskinen S, Hawthorne G, Sarajuuri J, Formisano R, Von Wild K, Neugebauer E, Wilson L, Gibbons H, Powell J, Bullinger M, Höfer S, Maas A, Zitnay G, Von Steinbuechel N. Qolibri Task Force. Quality of life after traumatic brain injury: the clinical use of the QOLIBRI, a novel disease-specific instrument. Brain Inj. 2010;24(11):1272-91.

35. Koskinen S, Hokkinen E-M, Wilson L, Sarajuuri J, von Steinbuechel N, Truelle Comparison of subjective and objective assessment of outcome after traumatic brain injury using the International Classification of functioning, disability and Health 8ICF). J-L. Disability and Rehabilitation. 2011; Early Online, 1-15.

36. von Steinbuechel N, Wilson L, Gibbons H, Muehlan H, Schmidt H, Schmidt S, Sasse N, Koskinen S, Sarajuuri J, Höfer S, Bullinger M, Maas A, Neugebauer E, Powell J, von Wild K, Zitnay G, Bakx W, Christensen A-L, Formisano R, Hawthorne G, Truelle J-L. QOLIBRI overall scale: a brief index of health-related quality of life after traumatic brain injury. J Neurol Neurosurg Psychiatry. 2012;83:1041-1047. 
37. Artman L, McMahon, B. Functional limitations in TBI and their relationship to job maintenance following work re-entry. Journal of Vocational Rehabilitation. 2013;39:13-21.

38. Gill CJ, Sander AM, Robins N, Mazzei DK, Struchen MA. Exploring experiences of intimacy from the viewpoint of individuals with traumatic brain injury and their partners. J Head Trauma Rehabil. 2011;26:56-68.

39. Wood RL, Liossi C, Wood L. The impact of head injury neurobehavioural sequelae on personal relationships: preliminary findings. Brain Inj. 2005;19:845-51.

40. Williams WH, Evans JJ. Brain injury and emotion: an overview to a special issue on biopsychosocial approaches in neurorehabilitation. Neuropsychol Rehabil. 2003;13:111.

41. Morton MV, Wehman P. Psychosocial and emotional sequelae of individuals with traumatic brain injury: a literature review and recommendations. Brain Inj. 1995;9:8192.

42. Bezner JR, Hunter DL. Wellness perception in persons with traumatic brain injury and its relation to functional independence. Arch Phys Med Rehabil. 2001; 82: 787-92.

43. van Velzen JM, van Bennekom CA, Edelaar MJ, Sluiter JK, Frings-Dresen MH. How many people return to work after acquired brain injury?: a systematic review. Brain Inj. 2009;23:473-88.

44. West MD, Targett PS, Crockatt SY, Wehman PH. Return to work following traumatic brain injury. In: Zasler ND, Douglas DI, Zafonte RD, editors. Brain injury medicine: principles and practice. 2nd ed. New York: Demos Medical Publishing; 2013. p. 134959. 
45. Keyser-Marcus LA, Bricout JC, Wehman P, Campbell LR, Cifu DX, Englander J, High W, Zafonte RD. Acute predictors of return to employment after traumatic brain injury: a longitudinal follow-up. Arch Phys Med Rehabil. 2002;83:635-41.

46. Wehman PH, Kregel J, Keyser-Marcus L, Sherron-Targett P, Campbell L, West M, Cifu DX. Supported employment for persons with traumatic brain injury: a preliminary investigation of long-term follow-up costs and program efficiency. Arch Phys Med Rehabil. 2003;84:192-6.

47. Sander AM, Kreutzer JS, Fernandez CC. Neurobehavioral functioning, substance abuse, and employment after brain injury: implications for vocational rehabilitation. $\mathbf{J}$ Head Trauma Rehabil. 1997;12:28-41.

48. O’Neill J, Hibbard MR, Brown M, Jaffe M, Sliwinski M, Vandergoot D, Weiss MJ. The effect of employmenton quality of life and community integration after traumatic brain injury. J Head Trauma Rehabil. 1998;13:68-79. 


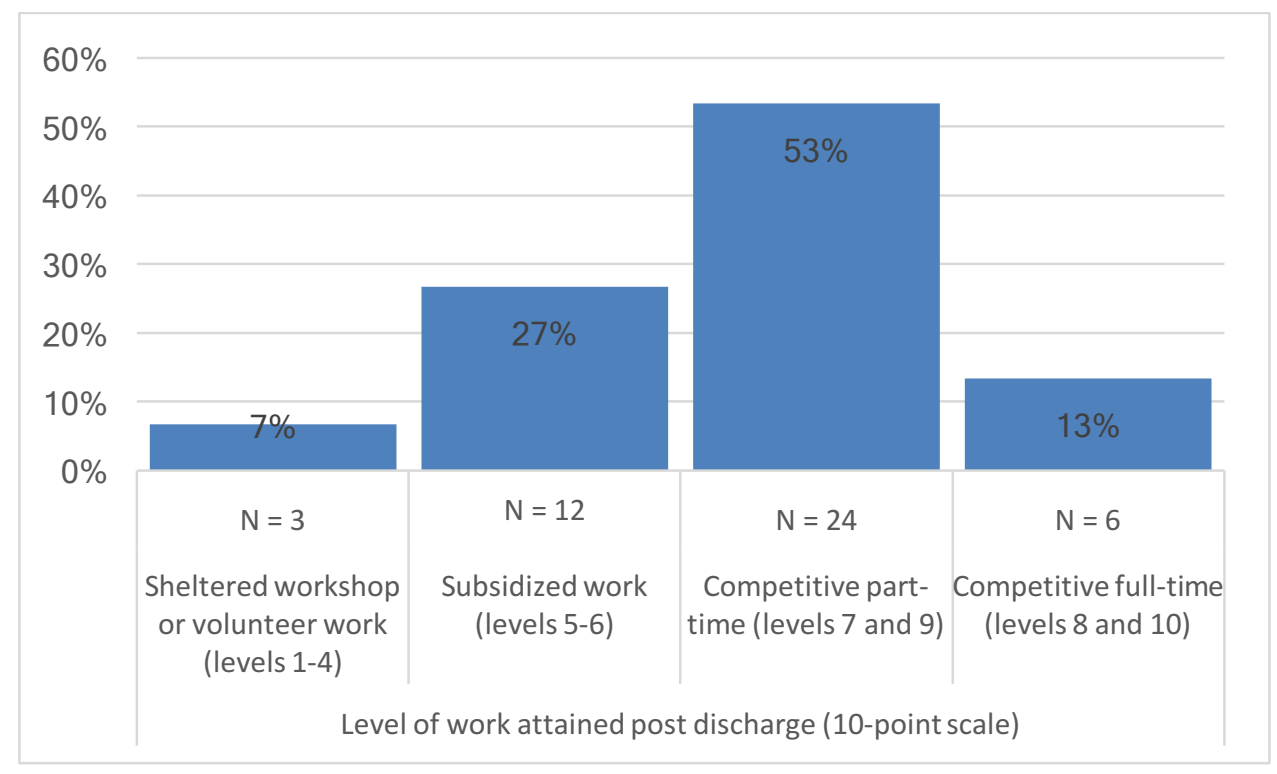

Figure 1 
Figure Legends:

Fig 1 Level of work competence attained after rehabilitation at the time of evaluation for the participants. 


\begin{tabular}{lcc}
\hline \multirow{2}{*}{ Areas } & \multicolumn{2}{c}{ Rating Scale } \\
\cline { 3 - 4 }
\end{tabular}

1. My effort during rehabilitation to overcome the difficulties that were caused by my brain injury has been:

2. Although different from what it was before my brain injury, my present life is:

3. Since rehabilitation, I have been leading a/an:

4. After rehabilitation I feel that I am:

5. My social life following rehabilitation is:

6. My ability to establish intimate relationships is:
Nothing special

Unproductive life

Still not at peace with myself

Most unsatisfactory

Very poor

\section{Outstanding} accomplishment

Very meaningful

Most productive life

Completely at peace with myself

Very satisfactory

Excellent 
Table 2 Demographic and clinical characteristics of the study sample $(n=45)$

\begin{tabular}{|c|c|c|}
\hline Variable & & $\%$ or Mean (SD, Range) \\
\hline Men & & 75.6 \\
\hline Age at injury $(y)$ & & $30.1(10.3,15.0-52.0)$ \\
\hline Time between injury and evaluation (y) & & $9.7(5.5,4.0-36.0)$ \\
\hline Time at work post discharge $(\mathrm{y})$ & & $4.7(2.3,0.7-8.0)$ \\
\hline \multicolumn{3}{|l|}{ Education (y) } \\
\hline Basic & & 13.3 \\
\hline Upper secondary & & 75.6 \\
\hline Higher & & 11.1 \\
\hline \multicolumn{3}{|l|}{ Mechanism of injury } \\
\hline Motor vehicle collision & & 31.1 \\
\hline Bicycle collision & & 31.1 \\
\hline Pedestrian-auto collision & & 8.9 \\
\hline Assault & & 6.7 \\
\hline Other (fall, hit by an object) & & 17.8 \\
\hline Unknown & & 4.4 \\
\hline \multicolumn{3}{|l|}{ Posttraumatic amnesia } \\
\hline$<24 \mathrm{~h}$ & & 4.4 \\
\hline $1-7 \mathrm{~d}$ & & 8.9 \\
\hline $1-4 \mathrm{w}$ & & 28.9 \\
\hline$>4 \mathrm{w}$ & & 51.1 \\
\hline Not assessable or unknown & & 6.7 \\
\hline \multicolumn{3}{|l|}{ Brain CT/MRI findings } \\
\hline $\mathrm{CH}$ & & 84.4 \\
\hline DAI & & 26.7 \\
\hline $\mathrm{ICP}$ & & 37.8 \\
\hline None & & 4.4 \\
\hline \multicolumn{3}{|l|}{ Estimated pre-injury adjustment } \\
\hline \multirow[t]{4}{*}{ Personal } & Consistently good & 48.9 \\
\hline & Mostly satisfactory & 26.7 \\
\hline & Slightly problematic & 22.2 \\
\hline & $\begin{array}{l}\text { Considerably } \\
\text { problematic }\end{array}$ & 2.2 \\
\hline \multirow[t]{4}{*}{ Vocational } & Consistently good & 68.9 \\
\hline & Mostly satisfactory & 11.1 \\
\hline & Slightly problematic & 17.8 \\
\hline & $\begin{array}{l}\text { Considerably } \\
\text { problematic }\end{array}$ & 2.2 \\
\hline \multirow[t]{4}{*}{ Social } & Consistently good & 55.6 \\
\hline & Mostly satisfactory & 28.9 \\
\hline & Slightly problematic & 13.3 \\
\hline & $\begin{array}{l}\text { Considerably } \\
\text { problematic }\end{array}$ & 2.2 \\
\hline \multicolumn{3}{|l|}{ Level of intellectual functioning } \\
\hline Within the borderline range; $65-80$ & & 2.2 \\
\hline Within the average range; $80-110$ & & 44.4 \\
\hline Within the high average range; $110-120$ & & 40.0 \\
\hline Within the superior range, $>120$ & & 13.3 \\
\hline
\end{tabular}



Table 3 Results of self-appraisals for the participants $(n=45)$

\begin{tabular}{|c|c|c|c|c|c|c|}
\hline Six areas of self-appraisal & Mean & Median & Q1 & Q3 & Minimum & Maximum \\
\hline Effort during rehabilitation & 8,6 & 9,0 & 8,0 & 9,0 & 5,0 & 10,0 \\
\hline Meaningfulness in life & 8,1 & 8,0 & 7,0 & 9,0 & 4,0 & 10,0 \\
\hline Productivity in life & 8,3 & 8,0 & 8,0 & 9,0 & 4,0 & 10,0 \\
\hline At peace with oneself & 7,9 & 8,0 & 7,0 & 9,0 & 4,0 & 10,0 \\
\hline Satisfaction with social life & 7,7 & 8,0 & 7,0 & 9,0 & 3,0 & 10,0 \\
\hline $\begin{array}{l}\text { Ability to establish intimate } \\
\text { relationships }\end{array}$ & 7,4 & 8,0 & 7,0 & 8,0 & 3,0 & 10,0 \\
\hline Sum of self-ratings & 48,0 & 49,0 & 45,0 & 51,0 & 33,0 & 58,0 \\
\hline
\end{tabular}

Abbreviations: Q1, lower quartile; Q3, upper quartile 


\begin{tabular}{|c|c|c|c|c|}
\hline Six areas of self-appraisal & OR & $95 \% \mathrm{CI}$ & $P$ & \multirow{4}{*}{$\begin{array}{l}\text { Table } 4 \text { Three-category } \\
\text { level of work attained post } \\
\text { discharge explained by one area } \\
\text { of self-appraisal at a time using } \\
\text { univariate ordinal regression } \\
\text { analysis }\end{array}$} \\
\hline Effort during rehabilitation & 1.40 & $0.83-2.36$ & 0.21 & \\
\hline Meaningfulness in life & 1.22 & $0.80-1.86$ & 0.37 & \\
\hline Productivity in life & 0.76 & $0.47-1.23$ & 0.26 & \\
\hline At peace with oneself & 1.28 & $0.88-1.85$ & 0.20 & \\
\hline Satisfaction with social life & 0.98 & $0.66-1.46$ & 0.93 & \\
\hline $\begin{array}{l}\text { Ability to establish intimate } \\
\text { relationships }\end{array}$ & 1.79 & $1.20-2.68$ & 0.005 & \\
\hline Sum of self-ratings & 1.08 & $0.97-1.21$ & 0.16 & \\
\hline
\end{tabular}

Abbreviation: CI, confidence interval; OR, odds ratio 
APPENDIX 1. SCALE FOR SCORING PRE-INJURY OCCUPATION AND POST

REHABILITATION WORK COMPETENCE (Ben-Yishay \& Diller 2006)

Description

Score

Resumed full-time (competitive) compensated work in job for which

the subject received academic training pre-injury

Resumed part-time employment only as above

9

Attained full-time competitive employment in a clerical or skillful work

capacity acquired by on-the job training post rehabilitation

Attained part-time competitive employment only as above

Attained full-time subsidized work ability (in any area)

6

Attained part-time subsidized work ability only as above

Attained full-time volunteer (i.e. non-compensated) work ability

Attained part-time volunteer work ability (only)

Attained work ability in a sheltered workshop (only)

Attained no work ability even in a sheltered workshop 